\title{
Aspirin and clopidogrel use in the early postoperative period following on-pump and off-pump coronary artery bypass grafting
}

\author{
Dae Hyun Kim, MD, MPH, ${ }^{\mathrm{a}}$ Constantine Daskalakis, ScD, ${ }^{\mathrm{b}}$ Scott C. Silvestry, MD, ${ }^{\mathrm{c}}$ Mital P. Sheth, MD, ${ }^{\mathrm{d}}$ \\ Andrew N. Lee, MD, ${ }^{\mathrm{e}}$ Suzanne Adams, RN, MPH, ${ }^{\mathrm{e}}$ Sam Hohmann, PhD, ${ }^{\mathrm{f}}$ Sofia Medvedev, PhD, ${ }^{\mathrm{f}}$ and \\ David J. Whellan, MD, MHS
}

\begin{abstract}
Objective: Preoperative use of clopidogrel increases the risk of bleeding, but its postoperative use has not been studied. We studied early postoperative clopidogrel use in on-pump and off-pump coronary artery bypass grafting.
\end{abstract}

\begin{abstract}
Methods: Data were obtained from the University HealthSystem Consortium database. We conducted a retrospective analysis of data of 15,067 adults who had coronary artery bypass grafting between 2003 and 2006 and received perioperative aspirin alone or in combination with clopidogrel, with the latter administered within 2 days after coronary artery bypass grafting. Logistic regression was used to analyze in-hospital mortality, 30-day readmission, ischemic or thrombotic events, and bleeding events, with propensity score adjustment for clopidogrel treatment.
\end{abstract}

\begin{abstract}
Results: Combined aspirin and clopidogrel were used in 3268 patients $(22 \%)$. Compared with aspirin alone, aspirin plus clopidogrel was associated with reductions of in-hospital mortality $(0.95 \%$ vs $1.78 \%$; adjusted odds ratio: $0.50 ; 95 \%$ confidence interval: $0.25,0.99)$ and bleeding events $(4.19 \%$ vs $5.17 \%$; adjusted odds ratio: $0.70 ; 95 \%$ confidence interval: $0.51,0.97)$. Ischemic or thrombotic events were not significantly different $(1.29 \%$ vs $1.53 \%$; adjusted odds ratio, $0.99 ; 95 \%$ confidence interval: $0.59,1.64)$. The relative effect of combined treatment did not differ between on-pump and off-pump coronary artery bypass grafting.
\end{abstract}

Conclusions: Early postoperative clopidogrel combined with aspirin may be safe and beneficial compared with perioperative aspirin treatment alone, in both on-pump and off-pump coronary artery bypass grafting. However, a possibility of selection bias calls for randomized controlled trials to confirm our findings. (J Thorac Cardiovasc Surg 2009;138:1377-84)

Coronary artery bypass grafting $(\mathrm{CABG})$ without cardiopulmonary bypass ("off-pump") is associated with lower short-term mortality and morbidity than CABG with cardiopulmonary bypass ("'on-pump"),,${ }^{1,2}$ but concerns have been raised about a potential prothrombotic state after off-pump $\mathrm{CABG}^{3-5}$ In addition, perioperative aspirin therapy improves graft patency, prevents ischemic events, and prolongs survival, ${ }^{6-8}$ although aspirin resistance is common after $\mathrm{CABG},{ }^{9,10}$ in part due to cardiopulmonary bypass. ${ }^{11,12}$ To improve outcomes after CABG, more aggressive antiplatelet treatment with aspirin and clopidogrel may be warranted.

Data on the benefit and safety of clopidogrel use in patients having CABG mainly come from 2 randomized controlled trials. In the Clopidogrel in Unstable angina to

\footnotetext{
From the Department of Medicine, ${ }^{a}$ Beth Israel Deaconess Medical Center, Boston, Mass; Division of Biostatistics, ${ }^{\mathrm{b}}$ Department of Surgery, ${ }^{\mathrm{c}}$ Department of Medicine, ${ }^{\mathrm{e}}$ and Division of Cardiology, ${ }^{\mathrm{g}}$ Jefferson Medical College, Philadelphia, Pa; Hamilton Cardiology Associates, ${ }^{\mathrm{d}}$ Hamilton, NJ; and University HealthSystem Consortium, ${ }^{\mathrm{f}}$ Oak Brook, Ill.

Received for publication Nov 13, 2008; revisions received May 20, 2009; accepted for publication July 6, 2009.

Address for reprints: Dae Hyun Kim, MD, MPH, 110 Francis Street, Suite 1B, Boston, MA 02215 (E-mail: dkim2@bidmc.harvard.edu).

$0022-5223 / \$ 36.00$

Copyright (C) 2009 by The American Association for Thoracic Surgery

doi:10.1016/j.jtcvs.2009.07.027
}

prevent Recurrent ischemic Events (CURE) trial, the administration of clopidogrel, along with aspirin, improved cardiovascular outcomes in patients with non-ST segment elevation acute coronary syndromes, including those patients having $\mathrm{CABG}{ }^{13,14}$ In this trial, clopidogrel was stopped for a median of 10 days after CABG at the discretion of the surgeons. A post hoc analysis suggested an increased risk of bleeding associated with clopidogrel within 5 days before CABG. ${ }^{14}$ The Clopidogrel Versus Aspirin in Patients at Risk of Ischemic Events (CAPRIE) trial showed a longterm benefit of clopidogrel compared with aspirin among patients who had cardiac surgery in the past. ${ }^{15}$ But these results cannot be extrapolated to the perioperative period. In addition, clopidogrel alone may not provide effective platelet inhibition in the early postoperative period. ${ }^{16}$

Thus, the optimal perioperative antiplatelet therapy remains to be determined. Compared with preoperative use, the benefit and safety of clopidogrel use in the early postoperative period of CABG in addition to aspirin have been suggested in a few small observational studies in off-pump CABG ${ }^{17-20}$ Less evidence exists on such therapy in on-pump CABG. ${ }^{20}$

Our study analyzed data collected from 52 academic medical centers and affiliate hospitals in the United States during a 4-year period (2003-2006). We hypothesized that, in patients having $\mathrm{CABG}$, early postoperative administration of 


\section{Abbreviations and Acronyms \\ AHRQ = Agency for Healthcare Research and Quality \\ CABG = coronary artery bypass grafting \\ CI $=$ confidence interval \\ ICD-9-CM = International Classification of \\ Diseases, 9th Edition, Clinical \\ Modification \\ $\mathrm{OR} \quad=$ odds ratio \\ UHC = University HealthSystem Consortium}

clopidogrel in addition to perioperative use of aspirin improves short-term outcomes without significantly increasing bleeding complications compared with aspirin alone. We also explored whether the effect of such dual antiplatelet therapy (vs aspirin alone) differs between on-pump and off-pump CABG.

\section{METHODS}

\section{Database and Study Design}

The University HealthSystem Consortium (UHC) database is a clinical, administrative, and financial database compiled from academic medical centers and affiliate community hospitals to improve their clinical and operating efficiencies by pooling the data and providing benchmark measures. ${ }^{21}$ Data were extracted for the period between January 1, 2003, and December 31, 2006. Discharge abstracts were used to obtain sociodemographic characteristics, admission source and status, 29 comorbidities defined by the Agency for Healthcare Research and Quality (AHRQ), ${ }^{22}$ and postoperative outcomes. All diagnoses and procedures were coded using the International Classification of Diseases, 9th Edition, Clinical Modification (ICD-9-CM). Pharmacy records of when a medication was prescribed were used to determine medication use. Test results and details of procedures were not available in the UHC database. In addition, we included hospital-level characteristics by linking to the American Hospital Association Guide. ${ }^{23}$ This was unfunded work; our analyses were approved by the Institutional Review Board of Thomas Jefferson University, and informed consent was waived.

Discharges were eligible if a patient was: (1) 18 years or older; (2) had CABG, as captured by ICD-9-CM procedure codes 36.1X; and (3) had received perioperative aspirin (at least 2 doses between 5 days before and 2 days after $\mathrm{CABG}$ ). Patients were excluded if clopidogrel was started in the preoperative period (between 5 days before and 1 day before $\mathrm{CABG}$ ) or in the late postoperative period (later than 2 days after $\mathrm{CABG}$ ). Information on dosage of clopidogrel (with or without loading dose) was not consistently available and therefore not included in the analysis. We did not consider preoperative clopidogrel use, because patients who required it may differ significantly from those who did not, and because it has already been shown to be associated with major bleeding events. ${ }^{14,24-28}$ Similarly, we did not include late postoperative clopidogrel use due to data limitations; the date of adverse events was not recorded in the UHC database and therefore it would be impossible to determine whether clopidogrel might have been started as a result of ischemic or thrombotic events. Additional exclusion criteria were (1) hospitalization longer than 1 week prior to CABG; (2) concomitant valvular procedure; (3) warfarin use during the index hospitalization; and (4) missing or potentially erroneous information on key variables. These criteria were used to strengthen the homogeneity of the analysis sample and minimize confounding by case-mix.

\section{Study Outcomes and Other Covariates}

The primary study outcome was in-hospital mortality. We also examined 30-day readmission rate, ischemic or thrombotic events (defined as postoperative acute myocardial infarction, stroke, and venous thromboembolism), and any bleeding events (defined as postprocedural hemorrhage or hematoma and gastrointestinal hemorrhage). Diagnosis of each complication was made retrospectively using the UHC Complication Profiler that uses specific algorithms based on ICD-9-CM codes and diagnosis-related group lists. We compared perioperative aspirin plus clopidogrel in the early postoperative period versus perioperative aspirin alone on each of the above outcomes, with adjustment for a number of patient and hospital characteristics.

We accounted for the following patient characteristics: age; sex; race; primary payer; admission source and status; acute coronary syndrome (captured by ICD-9-CM diagnosis codes 410.X for acute myocardial infarction and 411.1 and 411.8X for unstable angina); 29 AHRQ-defined comorbidities (congestive heart failure, valvular disease, pulmonary circulation disorders, peripheral vascular disorders, hypertension, paralysis, other neurologic disorders, chronic pulmonary disease, diabetes with or without chronic complications, hypothyroidism, renal failure, liver disease, chronic peptic ulcer disease, HIV and AIDS, lymphoma, metastatic cancer, solid tumor without metastasis, rheumatoid arthritis and collagen vascular diseases, coagulation deficiency, obesity, weight loss, fluid and electrolyte disorders, blood loss anemia, deficiency anemia, alcohol abuse, drug abuse, psychoses, and depression) ${ }^{22}$; perioperative medication use (angiotensin converting enzyme inhibitors or angiotensin receptor blockers, beta-blockers, calcium channel blockers, direct thrombin inhibitor, diuretics, heparin, lipid-lowering agents, low-molecular-weight heparin, nonsteroidal anti-inflammatory drugs, and vasopressors or inotropes); type of CABG (onpump vs off-pump; captured by ICD-9-CM procedure code 39.61); and number of bypass grafts. The All Patient Refined-Diagnosis Related Group diagnosis code, severity of illness, and risk of mortality (3 M Health Information Systems, Minneapolis, Minn) ${ }^{29}$ were also included, because they have been shown to be a valid method of risk adjustment in CABG. ${ }^{30,31}$

We also accounted for the following hospital characteristics: hospital CABG volume, proportion of off-pump CABG, number of beds, membership in the Council of Teaching Hospitals, profit status, location (urban vs rural), and geographical region. Hospital CABG volume, defined as the number of $\mathrm{CABG}$ procedures performed at a hospital in a year $(<100$, 100-299, 300-499, and $\geq 500 / y$ ), and proportion of off-pump CABG were treated as time-dependent variables. Geographical region was defined according to the US census (Northeast, Midwest, South, and West). ${ }^{32}$

\section{Statistical Analysis}

We used logistic regression to compare aspirin plus clopidogrel versus aspirin alone. Because the decision to use clopidogrel in addition to aspirin is typically not made in a random manner, the characteristics of patients who receive both aspirin and clopidogrel are likely to differ from those of patients who receive aspirin alone. Due to the low event rates of most study outcomes, it was not feasible to include all measured variables in a multivariable model. Therefore, we used the propensity score approach. ${ }^{33}$

In estimating the propensity score, we modeled the likelihood of receiving aspirin plus clopidogrel versus aspirin alone as a function of all covariates. We started with a base model that included all the patient-level and hospital-level covariates listed above, and then checked the addition of all 2 -way interactions, one at a time. We fit a model with all main effects plus any 2-way interactions significant at the 0.10 level in the previous step. Finally, we conducted a stepwise backward elimination, retaining all main effects, and all interactions significant at the 0.10 level. Based on this final model, we estimated the propensity score for receiving aspirin plus clopidogrel versus aspirin alone.

The main analyses consisted of a logistic regression model for each outcome. Each model included treatment group, as well as the propensity score (in 10 equal-size groups, "deciles"). We also carried out 2 subgroup analyses for each outcome. The first analysis examined the difference between the 2 


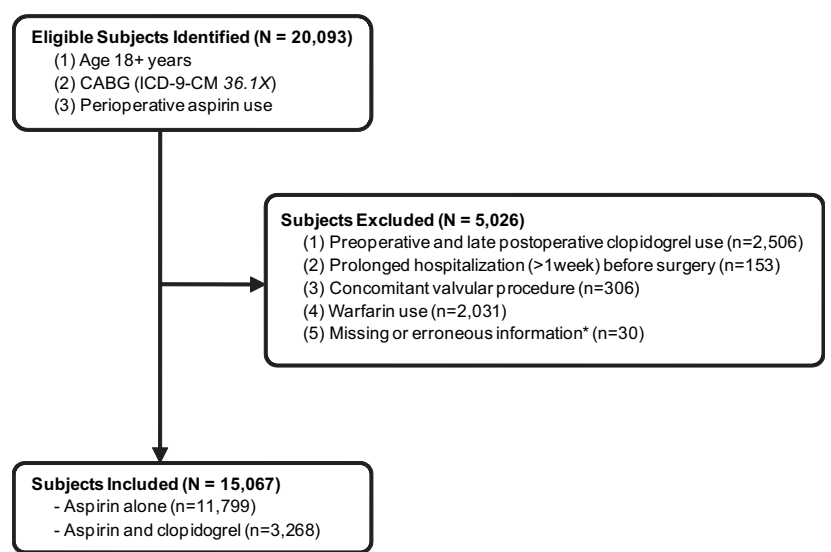

FIGURE 1. Selection of study sample. *Number of bypass grafts was unavailable for 8 cases. Procedure date preceded admission date in 22 subjects, which was considered as erroneous information. $C A B G$, Coronary artery bypass grafting; ICD-9-CM, International Classification of Diseases, 9th Edition, Clinical Modification.

treatment groups among on-pump and off-pump CABG and assessed the potential interaction between treatment and on-pump/off-pump CABG. The second analysis was restricted to patients without acute coronary syndrome. To account for the clustered nature of data (by hospital), the logistic regression models used the Generalized Estimation Equations approach, with the robust variance estimator. Propensity-adjusted odds ratios (ORs), 95\% confidence intervals (CIs), and $P$ values were computed from the models. All analyses were performed in Stata 9.2 (StataCorp, College Station, Tex).

\section{RESULTS}

Of a total of 20,093 adults who had CABG and received perioperative aspirin between January 1, 2003, and December $31,2006,5026$ were excluded based on prespecified criteria, leaving a final analytical sample of 15,067 patients (Figure 1). Patients had an average age (standard deviation) of 64 (11) years, and three-quarters of them were men.

A total of $3268(22 \%)$ patients received both aspirin and clopidogrel. This fraction varied widely across the 52 different hospitals represented in the data (median $=10.7 \%$; interquartile range: $5.4 \%-38.3 \%$ ) and was significantly lower in government-owned hospitals (Table 1). Patients who had peripheral vascular disease, received beta-blockers and direct thrombin inhibitors, and had off-pump CABG were also more likely to be treated with aspirin and clopidogrel, whereas those with peptic ulcer were less likely (Table 2). The median (interquartile range) for the estimated propensity score was $72.6 \%(30.4 \%-95.1 \%)$ for the aspirin-plus-clopidogrel group and 5.0\% $(1.5 \%-12.6 \%)$ for the aspirin-alone group.

\section{Main Analyses}

Patients who received both aspirin and clopidogrel had lower in-hospital mortality than those who received aspirin alone $(0.95 \%$ vs $1.78 \%$, propensity-adjusted $P=.048$, Table 3). However, the 2 groups appeared similar with
TABLE 1. Characteristics of hospitals with low versus high clopidogrel use

\begin{tabular}{|c|c|c|c|}
\hline & $\begin{array}{c}\text { Hospitals with } \\
\text { low aspirin }+ \\
\text { clopidogrel } \\
\text { use }^{*}(\mathbf{n}=\mathbf{2 6})\end{array}$ & 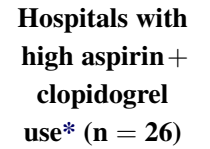 & $P$ \\
\hline $\begin{array}{l}\text { Aspirin + clopidogrel } \\
\text { use }(\%), \text { median } \\
\text { (IQR) }\end{array}$ & $5.4(1.3,8.3)$ & $38.3(26.1,58.9)$ & $<.001$ \\
\hline $\begin{array}{l}\text { Off-pump CABG } \\
\qquad \%), \text { median } \\
(\mathrm{IQR})\end{array}$ & $14.8(7.2,33.6)$ & $25.3(9.2,42.4)$ & .332 \\
\hline $\begin{array}{l}\text { Hospital annual } \\
\text { CABG volume } \\
\text { (cases/y), median } \\
\text { (IQR) }\end{array}$ & $143(96,237)$ & $186(120,296)$ & .194 \\
\hline $\begin{array}{r}\text { Number of beds, } \\
\text { median (IQR) }\end{array}$ & $505(432,686)$ & $603(476,744)$ & .103 \\
\hline $\begin{array}{l}\text { Membership in the } \\
\text { Council } \\
\text { of Teaching } \\
\text { hospitals, n }(\%)\end{array}$ & $25(96.2)$ & $25(96.2)$ & 1.000 \\
\hline Profit status, n (\%) & & & .008 \\
\hline Profit & $1(3.9)$ & $0(0.0)$ & \\
\hline Nonprofit & $7(26.9)$ & $18(69.2)$ & \\
\hline Government & $18(69.2)$ & $8(30.8)$ & \\
\hline Location, n (\%) & & & 1.000 \\
\hline Urban & $22(84.6)$ & $22(84.6)$ & \\
\hline Rural & $4(15.4)$ & $4(15.4)$ & \\
\hline $\begin{array}{c}\text { Geographical region, } \\
\mathrm{n}(\%)\end{array}$ & & & .471 \\
\hline South & $8(30.8)$ & $9(34.6)$ & \\
\hline Midwest & $10(38.4)$ & $5(19.2)$ & \\
\hline West & $4(15.4)$ & $6(23.1)$ & \\
\hline Northeast & $4(15.4)$ & $6(23.1)$ & \\
\hline
\end{tabular}

$I Q R$, Interquartile range; $C A B G$, coronary artery bypass grafting. *Hospitals were classified via a split at the median of aspirin and clopidogrel use $(10.7 \%)$; those with less than $10.7 \%$ use were classified as "low use," and those with $10.7 \%$ or higher were classified as "high use."

respect to ischemic or thrombotic events $(1.29 \%$ vs $1.53 \%$, $P=0.960$, Table 3), including acute myocardial infarction $(0.15 \%$ vs $0.11 \%)$, stroke $(0.80 \%$ vs $0.82 \%)$, and venous thromboembolism $(0.37 \%$ vs $0.61 \%)$. Because of the low event rate, we cannot exclude a substantial benefit for either treatment group (the aspirin-plus-clopidogrel group may be from $41 \%$ better up to $64 \%$ worse than the aspirin-alone group).

Surprisingly, bleeding events were also lower in the aspirin-plus-clopidogrel group than in the aspirin-alone group $(4.19 \%$ vs $5.17 \%, P=0.029$, Table 3$)$. This difference seemed to be mainly driven by the incidence of postprocedural hemorrhage or hematoma $(3.82 \%$ vs $5.01 \%)$ but not gastrointestinal hemorrhage $(0.52 \%$ vs $0.50 \%)$.

\section{Subgroup Analyses}

The relative effect of aspirin and clopidogrel use versus aspirin alone did not appear to differ significantly between 
TABLE 2. Selected patient characteristics and antiplatelet therapy

\begin{tabular}{|c|c|c|c|}
\hline & $\begin{array}{c}\text { Aspirin alone } \\
(\mathrm{n}=11,799)\end{array}$ & $\begin{array}{c}\text { Aspirin }+ \\
\text { clopidogrel } \\
(\mathbf{n}=\mathbf{3 , 2 6 8})\end{array}$ & $P$ \\
\hline Age $(y), n(\%)$ & & & .458 \\
\hline$<60$ & $4301(36.4)$ & $1198(36.7)$ & \\
\hline $60-69$ & $3880(32.9)$ & $1064(32.6)$ & \\
\hline $70+$ & $3618(30.7)$ & $1003(30.7)$ & \\
\hline Sex, n $(\%)$ & & & .224 \\
\hline Male & $8895(75.5)$ & $2439(74.6)$ & \\
\hline Female & $2874(24.5)$ & $829(25.4)$ & \\
\hline Race, n (\%) & & & .177 \\
\hline White & $8166(69.2)$ & $2449(75.0)$ & \\
\hline Black & $1149(9.7)$ & $298(9.1)$ & \\
\hline Others & $2484(21.1)$ & $521(15.9)$ & \\
\hline $\begin{array}{l}\text { Acute coronary } \\
\text { syndrome, }{ }^{*} \mathrm{n}(\%)\end{array}$ & $2098(17.8)$ & $637(19.5)$ & .604 \\
\hline APR-DRG severity of illness, $n(\%)$ & & & .235 \\
\hline Mild & $1553(13.2)$ & $372(11.4)$ & \\
\hline Moderate & $5987(50.7)$ & $1636(50.1)$ & \\
\hline Severe & $3317(28.1)$ & $1007(30.8)$ & \\
\hline Extreme & $942(8.0)$ & $253(7.7)$ & \\
\hline APR-DRG risk of mortality, $n(\%)$ & & & .350 \\
\hline Mild & $4496(38.1)$ & $1119(34.2)$ & \\
\hline Moderate & $4494(38.1)$ & $1276(39.1)$ & \\
\hline Severe & $2129(18.0)$ & $668(20.4)$ & \\
\hline Extreme & $680(5.8)$ & $205(6.3)$ & \\
\hline \multicolumn{4}{|l|}{ Comorbidities, n (\%) } \\
\hline Anemia & 1485 (12.6) & $395(12.1)$ & 644 \\
\hline Coagulopathy & $778(6.6)$ & $201(6.2)$ & .518 \\
\hline Congestive heart failure & $97(0.8)$ & $12(0.4)$ & .201 \\
\hline Diabetes mellitus & $4619(39.2)$ & $1316(40.3)$ & .222 \\
\hline Hypertension & $8343(70.7)$ & $2234(68.4)$ & .435 \\
\hline Peptic ulcer & $60(0.5)$ & $7(0.2)$ & .004 \\
\hline Peripheral vascular disease & $1482(12.6)$ & $477(14.6)$ & .004 \\
\hline Renal failure & $826(7.0)$ & $251(7.7)$ & .587 \\
\hline \multicolumn{4}{|l|}{ Perioperative medication use, $\mathrm{n}(\%)$} \\
\hline ACE inhibitors or ARBs & $6054(51.3)$ & $1673(51.2)$ & .570 \\
\hline Beta-blockers & $11,286(95.7)$ & $3174(97.1)$ & .033 \\
\hline Calcium channel blockers & $4487(38.0)$ & $1278(39.1)$ & .197 \\
\hline Direct thrombin inhibitors & $138(1.2)$ & $46(1.4)$ & .001 \\
\hline Diuretics & $11,459(97.1)$ & $2983(91.3)$ & .128 \\
\hline Heparin & $10,563(89.5)$ & $3040(93.0)$ & .787 \\
\hline Lipid-lowering agents & $9843(83.4)$ & $2727(83.5)$ & .055 \\
\hline Low-molecular-weight heparin & $1903(16.1)$ & $487(14.9)$ & .070 \\
\hline NSAIDs & $4228(35.8)$ & $1281(39.2)$ & .543 \\
\hline Vasopressors or inotropes & 9879 (83.7) & $2934(89.8)$ & .378 \\
\hline Cardiopulmonary bypass, $\mathrm{n}(\%)$ & & & .001 \\
\hline Off-pump CABG & $2852(24.2)$ & $1567(48.0)$ & \\
\hline On-pump CABG & $8947(75.8)$ & $1701(52.0)$ & \\
\hline Number of bypass grafts, $n(\%)$ & & & .089 \\
\hline 1 & $2811(23.8)$ & $840(25.7)$ & \\
\hline 2 & $4825(40.9)$ & $1298(39.7)$ & \\
\hline 3 & $3212(27.2)$ & $843(25.8)$ & \\
\hline $4+$ & $951(8.1)$ & $287(8.8)$ & \\
\hline
\end{tabular}

$\overline{A P R-D R G}$, All Patient Refined-Diagnosis Related Group; $A C E$, angiotensin converting enzyme; $A R B$, angiotensin receptor blocker; NSAID, nonsteroidal anti-inflammatory drug; $C A B G$, coronary artery bypass grafting. *Acute coronary syndrome includes acute myocardial infarction and unstable angina. on-pump and off-pump CABG groups (Figure 2). Furthermore, the main results were similar when the analyses were restricted to patients without acute coronary syndrome $(\mathrm{n}=12,332)$. The adjusted ORs $(95 \%$ CIs $)$ were $0.54(0.30$, $0.96)$ for in-hospital mortality, $0.83(0.61,1.12)$ for in-hospital mortality or 30-day readmission, $1.11(0.68,1.81)$ for ischemic or thrombotic events, and $0.64(0.45,0.91)$ for bleeding events.

\section{DISCUSSION}

Unlike in the setting of percutaneous coronary intervention, ${ }^{14,18}$ the role of combined aspirin and clopidogrel treatment has not been well-defined in the setting of CABG. Early postoperative administration of clopidogrel in addition to aspirin has already been adopted by clinicians, but the impact of such antiplatelet strategy has not been examined extensively. Given that preoperative aspirin and clopidogrel treatment is associated with increased risk of bleeding complications, ${ }^{14,24-28}$ we examined the benefit and safety of a different strategy of perioperative antiplatelet therapy. In a large database of adult CABG patients, we found that early postoperative clopidogrel administration in addition to perioperative aspirin treatment was associated with a $50 \%$ relative reduction of in-hospital mortality, compared with perioperative aspirin treatment alone. This benefit was present after adjustment for patient-level and hospital-level characteristics that affect the propensity to administer one type of treatment or the other. The results did not differ significantly across the use of cardiopulmonary bypass or when the analysis was limited to patients without acute coronary syndrome.

\section{Benefit and Safety of Early Postoperative Clopidogrel Use Combined with Aspirin}

Our study supports previous reports that administration of clopidogrel in the early postoperative period in addition to aspirin may be potentially beneficial and safe following off-pump CABG. Although preoperative aspirin and clopidogrel treatment has been evaluated in several observational studies, ${ }^{14,24-28}$ such therapy in the early postoperative period has been examined only in a few small samples of patients having off-pump CABG. ${ }^{17-20}$ These studies used predefined protocols that administer clopidogrel several hours after $\mathrm{CABG}$ and when chest tube drainage was reduced. In a retrospective analysis of 364 patients, Halkos and colleagues ${ }^{17}$ found that clopidogrel with an initial loading dose of 150 mg 4 hours postoperatively and a maintenance dose of 75 $\mathrm{mg}$ daily for 4 weeks (in addition to perioperative aspirin treatment) were associated with lower in-hospital mortality. In a prospective cohort study of 591 patients, Gurbuz and associates ${ }^{19}$ reported that clopidogrel administration on the first postoperative day without a loading dose for at least 30 days (in addition to aspirin) was associated with decreased adverse cardiac events and death, without an excess of bleeding events. In a prospective cohort study of 117 
TABLE 3. Study outcomes for patients having CABG

\begin{tabular}{|c|c|c|c|c|c|c|c|c|}
\hline \multirow[b]{3}{*}{ Outcomes } & \multicolumn{3}{|c|}{ Aspirin alone $(n=11,799)$} & \multicolumn{3}{|c|}{ Aspirin + clopidogrel $(n=3,268)$} & & \\
\hline & \multirow[b]{2}{*}{$\mathbf{n}$} & \multirow{2}{*}{$\begin{array}{c}\text { Unadjusted } \\
\text { rate }\end{array}$} & \multirow{2}{*}{$\begin{array}{l}\text { Estimated } \\
\text { rate }\end{array}$} & \multirow[b]{2}{*}{$\mathbf{n}$} & \multirow{2}{*}{$\begin{array}{c}\text { Unadjusted } \\
\text { rate }\end{array}$} & \multirow{2}{*}{$\begin{array}{l}\text { Estimated* } \\
\text { rate }\end{array}$} & \multicolumn{2}{|c|}{ Propensity-Adjusted } \\
\hline & & & & & & & OR $(95 \%$ CI $)$ & $\boldsymbol{P}$ \\
\hline In-hospital mortality & 210 & 1.78 & 1.59 & 31 & 0.95 & 0.81 & $0.50(0.25,0.99)$ & .048 \\
\hline $\begin{array}{l}\text { In-hospital mortality or 30-day } \\
\text { readmission }\end{array}$ & 1004 & 8.51 & 9.59 & 265 & 8.11 & 7.87 & $0.81(0.61,1.06)$ & .118 \\
\hline Ischemic/thrombotic events & 180 & 1.53 & 1.26 & 42 & 1.29 & 1.25 & $0.99(0.59,1.64)$ & .960 \\
\hline $\begin{array}{l}\text { In-hospital mortality or } \\
\text { ischemic/thrombotic events }\end{array}$ & 364 & 3.09 & 2.77 & 71 & 2.17 & 2.17 & $0.78(0.47,1.28)$ & .322 \\
\hline Bleeding events & 610 & 5.17 & 5.09 & 137 & 4.19 & 3.62 & $0.70(0.51,0.97)$ & .029 \\
\hline
\end{tabular}

$C A B G$, Coronary artery bypass grafting; $O R$, odds ratio; $C I$, confidence interval. *Estimated rates were calculated from the fifth decile of propensity score for receiving aspirin plus clopidogrel versus aspirin alone.

patients who had low chest tube drainage after on-pump and off-pump CABG, Chan and coworkers ${ }^{20}$ found no difference in bleeding complications between aspirin $81 \mathrm{mg}$ plus clopidogrel $75 \mathrm{mg}$ and aspirin $325 \mathrm{mg} .{ }^{20}$ Furthermore, a case series of 135 patients suggested the safety of aspirin and clopidogrel treatment when they were given 6 hours after off-pump CABG. ${ }^{18}$ Our study provides additional evidence of the short-term benefit and safety of early postoperative clopidogrel use combined with aspirin. Due to lack of information on dose, our findings should be interpreted as the effect of "typical" dose used in the real-world setting.

Several lines of evidence suggest that early administration of clopidogrel in addition to aspirin after CABG may reduce mortality and ischemic events. Aspirin and clopidogrel have been shown to reduce cardiovascular death, myocardial infarction, and stroke in patients with acute coronary syndrome $^{14,34}$ as well as in patient with established atherothrombotic disease. ${ }^{15}$ Although the benefits of clopidogrel on graft patency have not been examined, administration of ticlopidine in the early postoperative period was shown to improve graft patency ${ }^{35}$ and similar efficacy in coronary stenting has been reported between ticlopidine and clopidogrel. ${ }^{36}$ Experimental studies have shown that combined aspirin and clopidogrel inhibit thrombogenesis in graft. ${ }^{37}$ In the CURE trial, the benefits of clopidogrel started to emerge within 24 hours of initiation of treatment. ${ }^{38}$ Because early graft occlusion can occur as a result of platelet activation from endothelial damage and inflammatory cell activation, aspirin and clopidogrel treatment in the early postoperative period may prevent graft occlusion. An ongoing randomized controlled trial is evaluating the effects of early postoperative clopidogrel and aspirin versus aspirin alone on saphenous vein graft intimal hyperplasia following $\mathrm{CABG} .{ }^{39}$

\section{Benefit and Safety of Aspirin and Clopidogrel Use in On-Pump and Off-Pump CABG}

Our findings suggest that the benefit and safety of early postoperative clopidogrel administration in addition to

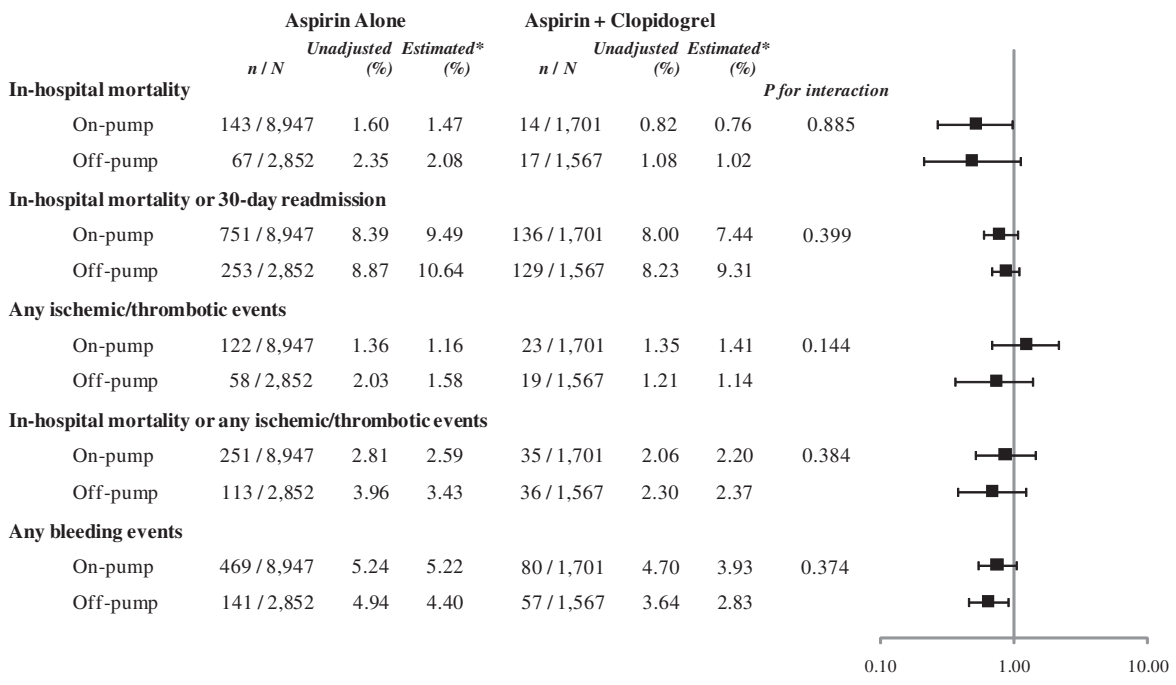

FIGURE 2. Study outcomes for patients having on-pump and off-pump coronary artery bypass grafting. *Estimated rates were calculated from the fifth decile of propensity score for receiving aspirin plus clopidogrel versus aspirin alone. 
aspirin exists in both on-pump and off-pump CABG. Although off-pump CABG has become popular due to its low short-term mortality and complication rates (especially hemorrhagic complications), ${ }^{1,2}$ some studies have found no differences in outcomes between on-pump and offpump $\mathrm{CABG}^{40}$ and a higher revascularization rate, ${ }^{41}$ due to a potentially prothrombotic state after off-pump CABG ${ }^{3-5}$ For this reason, the benefit and risk of perioperative antiplatelet therapy have been examined mainly in off-pump CABG, and limited information is available for on-pump CABG. ${ }^{20}$

However, it has been suggested that on-pump CABG is associated with an initial reduction in platelet count and subsequent enhanced regeneration of platelets that are not acetylated by aspirin, thereby conveying transient resistance to aspirin. ${ }^{11,12}$ Clinical significance and appropriate management of such aspirin resistance after on-pump CABG remain to be elucidated.

In-hospital mortality was lower in our analysis sample (1.5\% for on-pump CABG and $1.9 \%$ for off-pump $\mathrm{CABG})$ than that in the entire UHC database $(2.5 \%$ and $2.0 \%$ ) or in the Society of Thoracic Surgeons National Adult Cardiac Surgery Database $(2.9 \%$ and $2.3 \%))^{42}$ This may be explained by our exclusion of patients with higher risk of mortality, such as those who had concomitant valvular procedure, received preoperative clopidogrel, were treated with warfarin, or did not receive any antiplatelet treatment at all. The latter group, in particular, constituted two-thirds of the UHC CABG patients and had a relatively higher mortality $(2.4 \%)$. In contrast to previous reports, ${ }^{1,2}$ mortality appeared somewhat higher in off-pump CABG than in on-pump CABG in our sample. This discrepancy can be explained by the post hoc analysis showing that those who received antiplatelet treatment following on-pump CABG had lower risk of mortality than those who had on-pump CABG and did not receive antiplatelet treatment $(2.2 \%$ and $2.6 \%)$.

\section{Study Limitations}

Given that this is an observational cohort study in which clopidogrel use was determined by a surgeon's preference without randomization, our findings should be viewed with caution. The main concern is selection bias and residual confounding due to unmeasured factors that may be associated with patient outcomes and also influence the choice of treatment. Although we applied a propensity score analysis to reduce imbalance between the 2 treatment groups, this method cannot eliminate hidden bias due to unmeasured variables. In the UHC database, several pertinent clinical variables were not available, including dose of clopidogrel therapy (with or without loading dose), left ventricular systolic function, previous stents, transfusion requirement prior to or during operation, procedural characteristics, and postoperative chest tube output. Information on individual surgeon characteristics was also unavailable.
In our analyses, the observed reduction of in-hospital mortality associated with aspirin and clopidogrel use in both on-pump and off-pump CABG did not seem to be the result of a reduction of ischemic or thrombotic event rates. Most protocols used in prospective studies ${ }^{18-20}$ included administration of clopidogrel $75 \mathrm{mg}$ without a loading dose, which may not be effective enough to prevent ischemic or thrombotic events in the immediate postoperative period.

In addition, the date of ischemic or thrombotic events was unavailable in the UHC database, and therefore we were unable to determine whether clopidogrel was administered as a result of an ischemic or thrombotic event. It is possible that clopidogrel was prescribed after an ischemic or thrombotic event that occurred within 48 hours after surgery. If this were a common occurrence, such misclassification may explain the lack of effectiveness of combined treatment (compared with aspirin alone) in preventing ischemic or thrombotic events.

Another unexpected finding of our analyses was that bleeding events were significantly less common in the aspirin-plus-clopidogrel group than in the aspirin-alone group. Despite our propensity score adjustment, it is possible that unmeasured factors might have influenced surgeons to prescribe clopidogrel to patients with lower perceived risk of bleeding. In addition, if prescribing clopidogrel $75 \mathrm{mg}$ without a loading dose had been a common practice during study period, the bleeding risk might have been underestimated.

Bleeding events were not adjudicated across the sites according to standardized bleeding scales, so some misclassification has to be assumed. Furthermore, the actual cause of death and significance of bleeding events (ie, minor versus major) were not recorded in the UHC database. Therefore, we could not determine whether clopidogrel administration might have been delayed or not considered due to the significance of bleeding events. This might have possibly induced an apparent protective effect of the aspirin-plus-clopidogrel group (compared with aspirin alone) with respect to bleeding events.

Finally, because the duration of antiplatelet therapy after discharge, long-term mortality, and revascularization rates were not reported in the UHC database, we could not investigate the optimal duration and long-term benefit and risk of early postoperative clopidogrel use combined with aspirin. Although Gurbuz and colleagues ${ }^{19}$ reported no difference in adverse cardiac outcomes and mortality between shortterm users and long-term users of clopidogrel after offpump CABG, available evidence from the CURE ${ }^{13}$ and CAPRIE $^{15}$ trials suggest a long-term benefit of aspirin and clopidogrel in patients who are having $\mathrm{CABG}$ or those with a history of CABG.

\section{CONCLUSIONS}

In the absence of randomized controlled trials specifically assessing the efficacy and safety of more aggressive 
perioperative antiplatelet therapy in CABG, our study is the largest observational study to date to examine the benefit and safety of early postoperative clopidogrel administration in combination with perioperative aspirin treatment, among both on-pump and off-pump CABG. Given a significant increase in bleeding complications associated with its preoperative use, clopidogrel should be discontinued at least 5 days prior to CABG, according to current guidelines. ${ }^{43,44}$ However, when administered in the early postoperative period in addition to aspirin after postoperative bleeding complications are excluded, clopidogrel may be safe and beneficial compared with perioperative aspirin treatment alone among patients having on-pump and off-pump CABG. Due to limitations of our observational retrospective analyses of UHC data and the lack of detailed clinical information, our study does not provide clinicians with the information that is necessary to determine the risk-to-benefit ratio of early postoperative clopidogrel administration in individual patients. Therefore, more robust evidence from randomized controlled trials are much awaited.

\section{References}

1. Ascione R, Williams S, Lloyd CT, Sundaramoorthi T, Pitsis AA, Angelini GD. Reduced postoperative blood loss and transfusion requirement after beating-heart coronary operations: a prospective randomized study. J Thorac Cardiovasc Surg. 2001;121:689-696.

2. Hannan EL, Wu C, Smith CR, Higgins RS, Carlson RE, Culliford AT, et al. Off-pump versus on-pump coronary artery bypass graft surgery: differences in short-term outcomes and in long-term mortality and need for subsequent revascularization. Circulation. 2007;116:1145-1152.

3. Mariani MA, Gu YJ, Boonstra PW, Grandjean JG, van OW, Ebels T. Procoagulant activity after off-pump coronary operation: is the current anticoagulation adequate? Ann Thorac Surg. 1999;67:1370-71375.

4. Moller $\mathrm{CH}$, Steinbruchel DA. Platelet function after coronary artery bypass grafting: is there a procoagulant activity after off-pump compared with on-pump surgery? Scand Cardiovasc J. 2003;37:149-153.

5. Quigley RL, Fried DW, Pym J, Highbloom RY. Off-pump coronary artery bypass surgery may produce a hypercoagulable patient. Heart Surg Forum. 2003;6: 94-98.

6. Bybee KA, Powell BD, Valeti U, Rosales AG, Kopecky SL, Mullany C, et al. Preoperative aspirin therapy is associated with improved postoperative outcomes in patients undergoing coronary artery bypass grafting. Circulation. 2005;112(9 Suppl):I286-92 .

7. Dacey LJ, Munoz JJ, Johnson ER, Leavitt BJ, Maloney CT, Morton JR, et al. Effect of preoperative aspirin use on mortality in coronary artery bypass grafting patients. Ann Thorac Surg. 2000;70:1986-90.

8. Mangano DT. Aspirin and mortality from coronary bypass surgery. $N$ Engl J Med. 2002;347:1309-17.

9. Zimmermann N, Kienzle P, Weber AA, Winter J, Gams E, Schror K, et al. Aspirin resistance after coronary artery bypass grafting. J Thorac Cardiovasc Surg. 2001; 121:982-4.

10. Zimmermann N, Wenk A, Kim U, Kienzle P, Weber AA, Gams E, et al. Functional and biochemical evaluation of platelet aspirin resistance after coronary artery bypass surgery. Circulation. 2003;108:542-7.

11. Zimmermann N, Kurt M, Wenk A, Winter J, Gams E, Hohlfeld T. Is cardiopulmonary bypass a reason for aspirin resistance after coronary artery bypass grafting? Eur J Cardiothorac Surg. 2005;27:606-10.

12. Zimmermann N, Kurt M, Winter J, Gams E, Wenzel F, Hohlfeld T. Detection and duration of aspirin resistance after coronary artery bypass grafting. $J$ Thorac Cardiovasc Surg. 2008;135:947-8.

13. Fox KA, Mehta SR, Peters R, Zhao F, Lakkis N, Gersh BJ, et al. Benefits and risks of the combination of clopidogrel and aspirin in patients undergoing surgical revascularization for non-ST-elevation acute coronary syndrome: the Clopidogrel in Unstable angina to prevent Recurrent ischemic Events (CURE) Trial. Circulation. 2004:110:1202-8.
14. Yusuf S, Zhao F, Mehta SR, Chrolavicius S, Tognoni G, Fox KK. Effects of clopidogrel in addition to aspirin in patients with acute coronary syndromes without ST-segment elevation. N Engl J Med. 2001;345:494-502.

15. CAPRIE Steering Committee. A randomised, blinded, trial of clopidogrel versus aspirin in patients at risk of ischaemic events (CAPRIE). Lancet. 1996;348: 1329-39.

16. Lim E, Cornelissen J, Routledge T, Kirtland S, Charman SC, Bellm S, et al. Clopidogrel did not inhibit platelet function early after coronary bypass surgery: a prospective randomized trial. J Thorac Cardiovasc Surg. 2004;128:432-5.

17. Halkos ME, Cooper WA, Petersen R, Puskas JD, Lattouf OM, Craver JM, et al Early administration of clopidogrel is safe after off-pump coronary artery bypass surgery. Ann Thorac Surg. 2006;81:815-9.

18. Shennib H, Endo M, Benhameid O. A feasibility study of the safety and efficacy of a combined clopidogrel and aspirin regimen following off-pump coronary artery bypass grafting. Heart Surg Forum. 2003;6:288-91.

19. Gurbuz AT, Zia AA, Vuran AC, Cui H, Aytac A. Postoperative clopidogrel improves mid-term outcome after off-pump coronary artery bypass graft surgery: a prospective study. Eur J Cardiothorac Surg. 2006;29:190-5.

20. Chan V, Kulik A, Bourke ME, Ressler L, Mesana TG, Ruel M. Clopidogrel is safe early after on- and off-pump coronary artery bypass surgery. J Card Surg. 2007; 22:493-7.

21. University HealthSystem Consortium. Available at: www.uhc.edu. Accessed March 15, 2008

22. HCUP Comorbidity Software. Healthcare Cost and Utilization Project (HCUP) Agency for Healthcare Research and Quality, Rockville, MD. Available at: www.hcup-us.ahrq.gov/toolssoftware/comorbidity/comorbidity.jsp. Accessed Oct 30, 2006.

23. American Hospital Association. American Hospital Association Guide America's Directory of Hospitals and Health Care Systems. Chicago, IL: AHA Press; 2009.

24. Hongo RH, Ley J, Dick SE, Yee RR. The effect of clopidogrel in combination with aspirin when given before coronary artery bypass grafting. J Am Coll Cardiol. 2002;40:231-7.

25. Mehta RH, Roe MT, Mulgund J, Ohman EM, Cannon CP, Gibler WB, et al. Acute clopidogrel use and outcomes in patients with non-ST-segment elevation acute coronary syndromes undergoing coronary artery bypass surgery. J Am Coll Cardiol. 2006;48:281-6.

26. Kapetanakis EI, Medlam DA, Petro KR, Haile E, Hill PC, Dullum MK, et al. Effect of clopidogrel premedication in off-pump cardiac surgery: are we forfeiting the benefits of reduced hemorrhagic sequelae? Circulation. 2006;113:1667-74.

27. Vaccarino GN, Thierer J, Albertal M, Vrancic M, Piccinini F, Benzadon M, et al Impact of preoperative clopidogrel in off pump coronary artery bypass surgery: a propensity score analysis. J Thorac Cardiovasc Surg. 2009;137:309-13.

28. Chu MW, Wilson SR, Novick RJ, Stitt LW, Quantz MA. Does clopidogrel increase blood loss following coronary artery bypass surgery? Ann Thorac Surg. 2004;78:1536-41.

29. 3M Health Information Systems. Available at: http://solutions.3m.com/wps/ portal/3M/en_US/3MHIS/HealthInformationSystems. Accessed Oct 28, 2006.

30. Iezzoni LI, Ash AS, Shwartz M, Daley J, Hughes JS, Mackiernan YD. Judging hospitals by severity-adjusted mortality rates: the influence of the severityadjustment method. Am J Public Health. 1996;86:1379-87.

31. Landon B, Iezzoni LI, Ash AS, Shwartz M, Daley J, Hughes JS, et al. Judging hospitals by severity-adjusted mortality rates: the case of CABG surgery. Inquiry. 1996;33:155-66

32. US Census Bureau. Available at: www.census.gov. Accessed May 132007.

33. Rosenbaum $P$, Rubin D. The central role of the propensity score in observational studies for causal effects. Biometrika. 1983;70:41-55.

34. Mehta SR, Yusuf S, Peters RJ, Bertrand ME, Lewis BS, Natarajan MK, et al. Effects of pretreatment with clopidogrel and aspirin followed by long-term therapy in patients undergoing percutaneous coronary intervention: the PCI-CURE study. Lancet. 2001;358:527-33.

35. Limet R, David JL, Magotteaux P, Larock MP, Rigo P. Prevention of aortacoronary bypass graft occlusion. Beneficial effect of ticlopidine on early and late patency rates of venous coronary bypass grafts: a double-blind study. J Thorac Cardiovasc Surg. 1987;94:773-83.

36. Muller C, Buttner HJ, Petersen J, Roskamm H. A randomized comparison of clopidogrel and aspirin versus ticlopidine and aspirin after the placement of coronaryartery stents. Circulation. 2000;101:590-3.

37. Harker LA, Marzec UM, Kelly AB, Chronos NR, Sundell IB, Hanson SR, et al. Clopidogrel inhibition of stent, graft, and vascular thrombogenesis with antithrombotic enhancement by aspirin in nonhuman primates. Circulation. 1998;98:2461-9. 
38. Yusuf S, Mehta SR, Zhao F, Gersh BJ, Commerford PJ, Blumenthal M, et al. Early and late effects of clopidogrel in patients with acute coronary syndromes. Circulation. 2003;107:966-972.

39. Kulik A, Le MM, Wells GA, Mesana TG, Ruel M. The clopidogrel after surgery for coronary artery disease (CASCADE) randomized controlled trial: clopidogrel and aspirin versus aspirin alone after coronary bypass surgery [NCT00228423]. Curr Control Trials Cardiovasc Med. 2005;6:15.

40. Straka Z, Widimsky P, Jirasek K, Stros P, Votava J, Vanek T, et al. Off-pump versus on-pump coronary surgery: final results from a prospective randomized study PRAGUE-4. Ann Thorac Surg. 2004;77:789-793.

41. Williams ML, Muhlbaier LH, Schroder JN, Hata JA, Peterson ED, Smith PK, et al. Risk-adjusted short- and long-term outcomes for on-pump versus offpump coronary artery bypass surgery. Circulation. 2005;112(9 Suppl):I366-70.
42. Cleveland JC Jr, Shroyer AL, Chen AY, Peterson E, Grover FL. Off-pump coronary artery bypass grafting decreases risk-adjusted mortality and morbidity. Ann Thorac Surg. 2001;72:1282-8.

43. Anderson JL, Adams CD, Antman EM, Bridges CR, Califf RM, Casey DE Jr, et al. ACC/AHA 2007 guidelines for the management of patients with unstable angina/non-ST-Elevation myocardial infarction: a report of the American College of Cardiology/American Heart Association Task Force on Practice Guidelines. J Am Coll Cardiol. 2007;50:e1-57.

44. Antman EM, Hand M, Armstrong PW, Bates ER, Green LA, Halasyamani LK, et al. 2007 focused update of the ACC/AHA 2004 Guidelines for the Management of Patients with ST-Elevation Myocardial Infarction: a report of the American College of Cardiology/American Heart Association Task Force on Practice Guidelines. Circulation. 2008;117:296-329. 